\title{
Urban Food Security of the Colombo Metropolitan Region (CMR) in Covid times
}

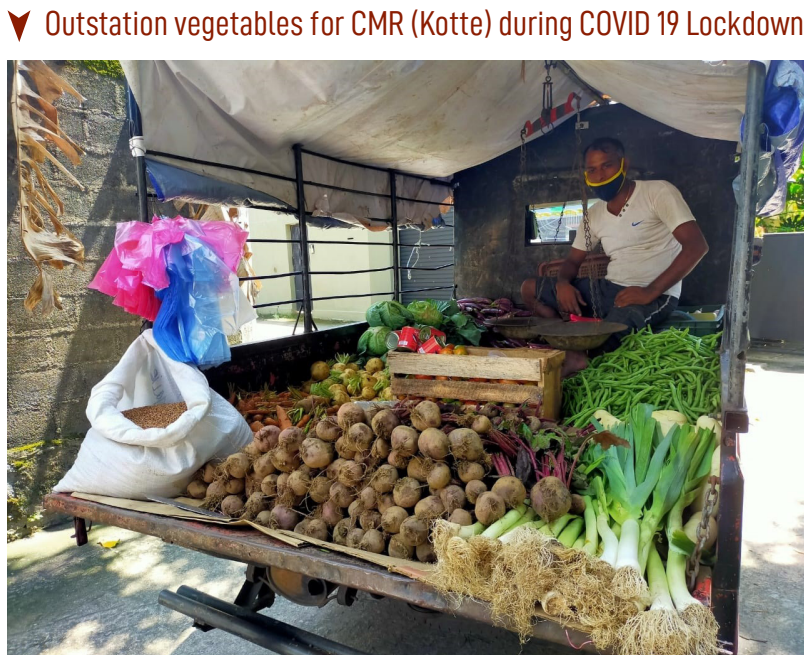

Home Visits: Mobile Vegetable Vendors from Upcountry Nuwaraeliya

\section{$\checkmark$ Interviews with CRFS actors}

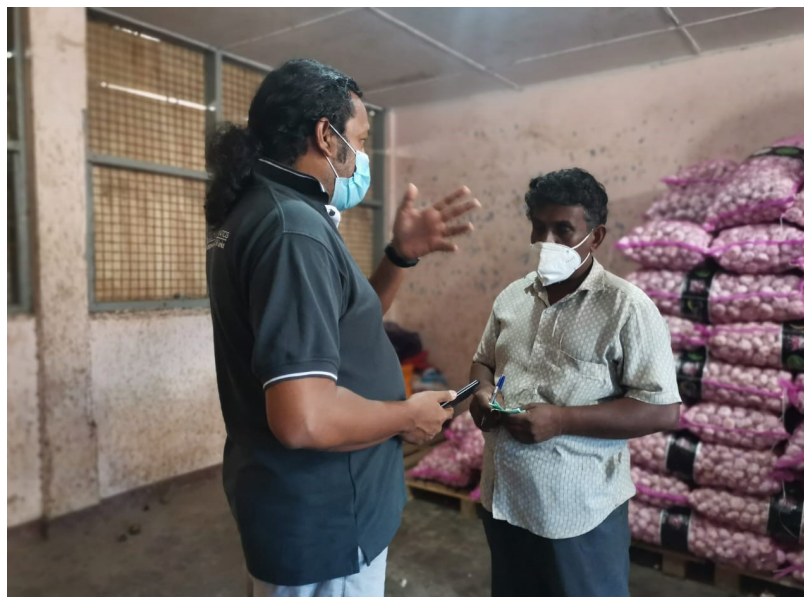

Author Interview a wholesale trader in Dambulla Economic Centre

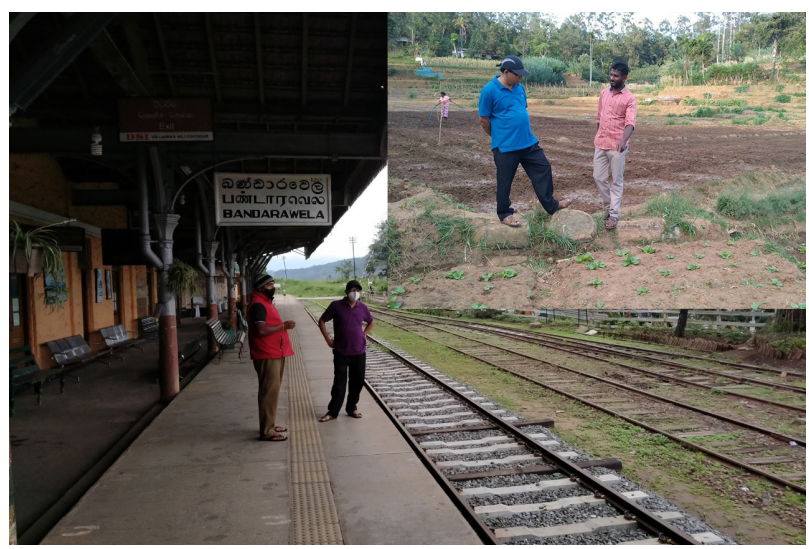

Co-Author interview commercial farmer in Welimada \& explore the solutions for vegetable logistics in Bandarawela
Colombo Municipality Region (CMR) consists of a highly complex food system that relies on the supply from distant outstations which literally collapsed during the pandemic situation. A requirement exists for empirical research to derive guidelines and recommendations to increase the sustainability and security in the food supply in CMR during a disaster situation.

\section{Research Objectives}

To investigate sources of urban food supply in CMR; identify the impacts for the City Region Food Supply System (CRFS) components during the COVID 19 \& recommend guidelines \& policies to address problems in the supply side of Urban Food System (UFS).

\section{Design/methodology/approach}

Qualitative thematic data analysis with purposive sampling with 25 respondents and face-to-face interviews were performed at the domicile of the CRFS actors, with many case studies.

\section{Originality/Social Value}

The first study is to use primary data to address the sustainability of UFS in CMR and helping farmers at origins and end urban consumers.

\section{Findings and Policy implications}

Sustainability of the food security within CMR, + Need some form of central and regional intervention during a pandemic to maintain the supply chain.

+ Alternative sources of food supplies - Peri-urban agriculture, Home gardening, Community farming at Grama Sevaka levels. 


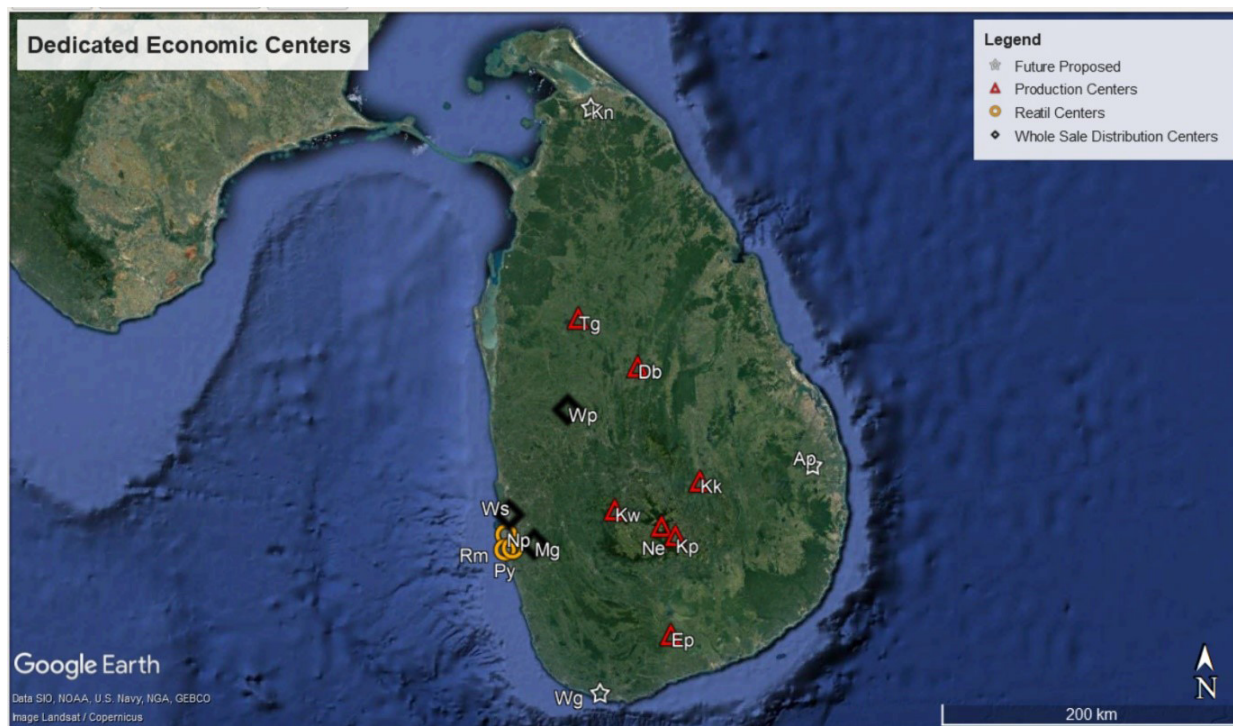

$\checkmark$ The study derived Urban Food Security Framework

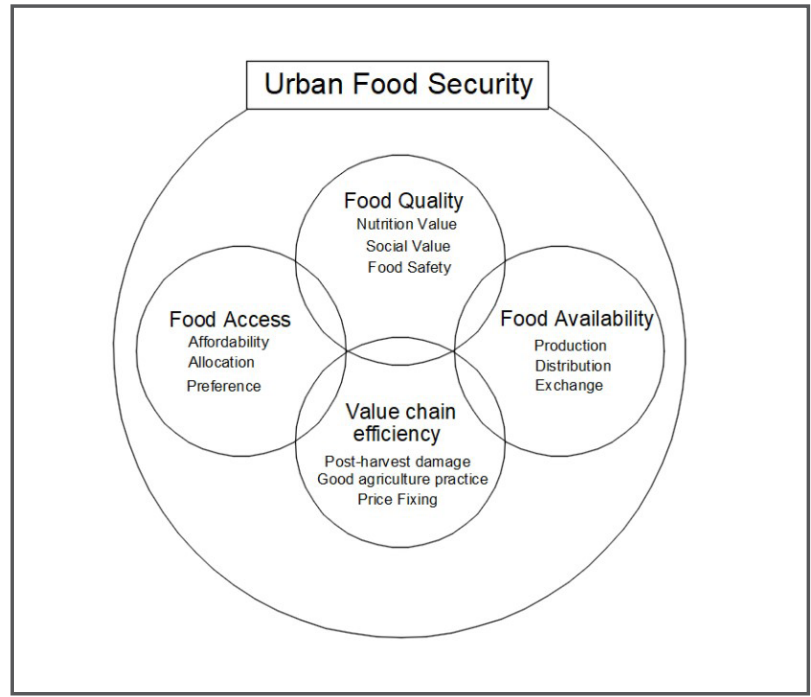

Author defined UFS framework built upon (Ford,2008)

Bad transportation - one of the root causes of post-harvest $\checkmark$ damage

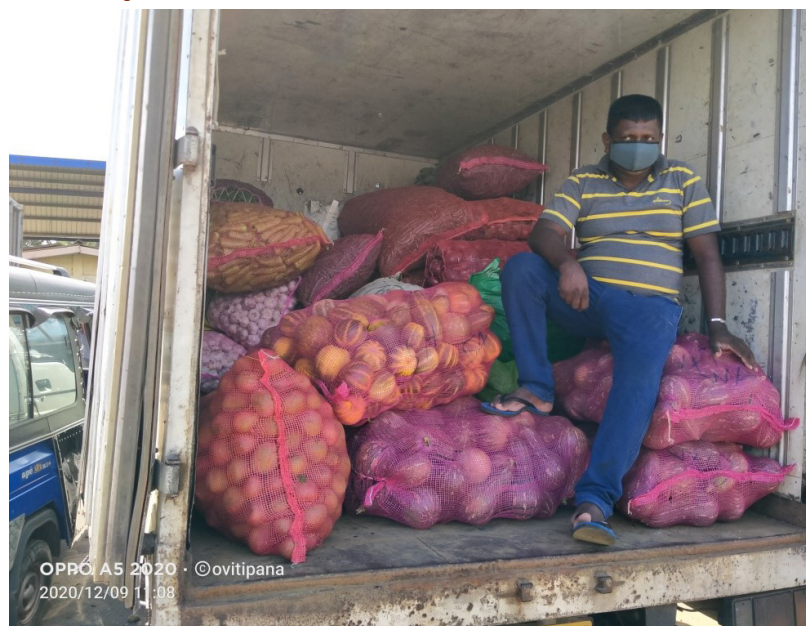

Dambulla Economic Center - wholesale vendor about to transport purchase to Colombo
$<$ Strategically located 'dedicated economic centres'

Dedicated economic centres in Sri Lanka

Exploiting the price slumps at outstations, converting retail to the wholesale business model during COVID 19 -

Narahenpita Economic Center $\checkmark$

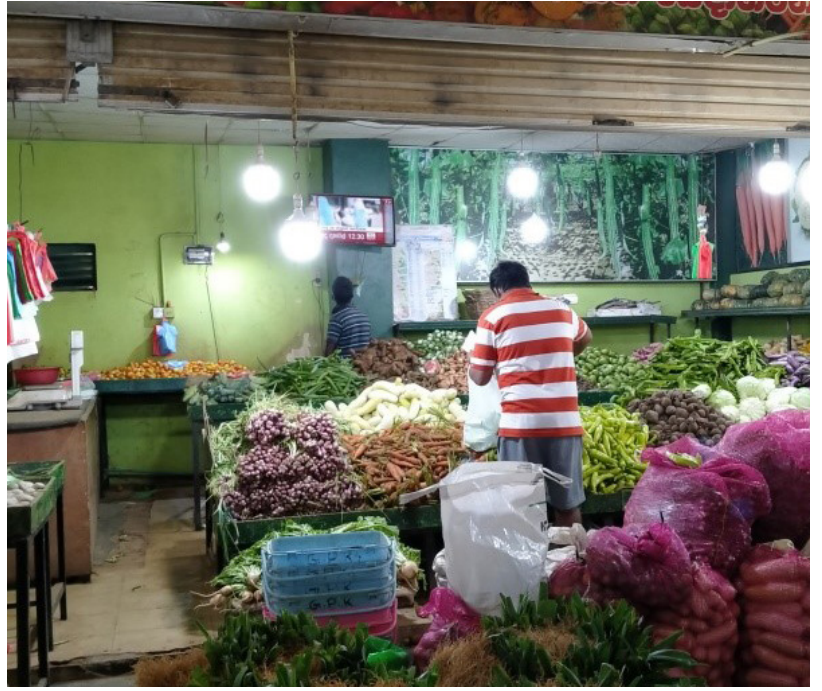

Retail business switching to wholesale model

Key Player in UFS discussion - Price fixing by commission $\checkmark$ broker damage

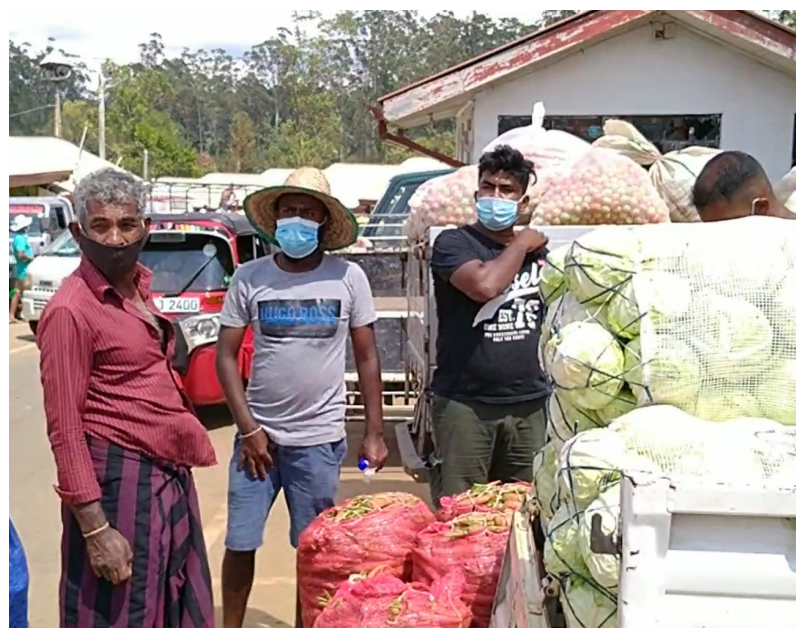

Commission Broker (In the middle of the picture) at Keppetipola Economic Center 
Picture Article

Refurbish abandoned and unused/under-utilized railway for vegetable transport

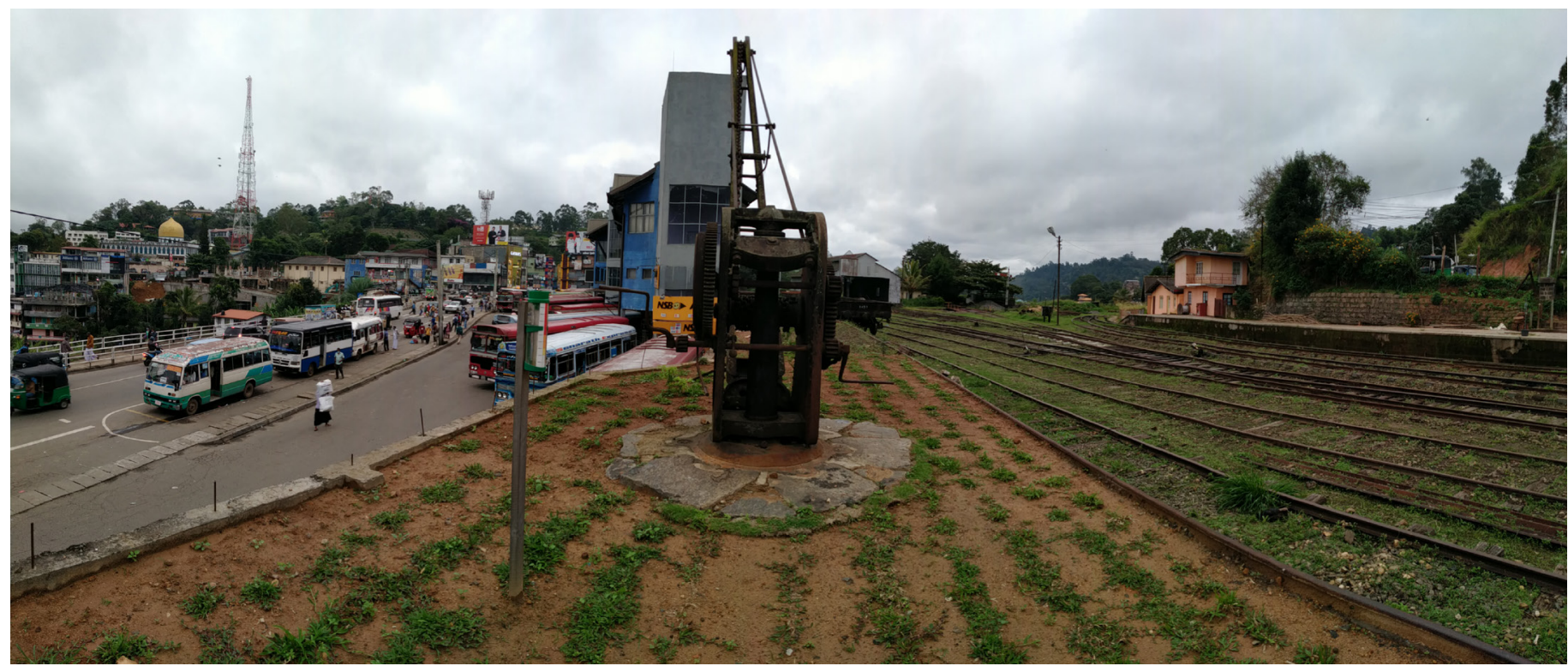

Abandoned logistic hub in Bandarawela linking road \& railway network

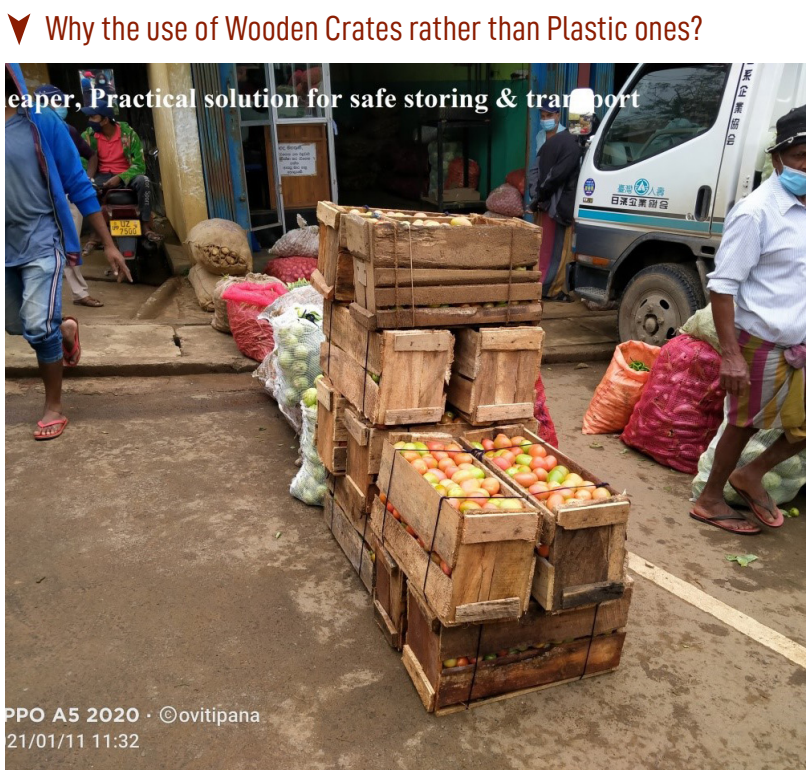

Cheaper, practical solution for safe storing \& transport

Efficient and effective vegetable value chain,

- Increase connectivity within value chain partners.

- Increase information transparency of demand \& supply.

- Encourage traditional 'attam kramaya' which has the character of EOS \& resource sharing.

Information sharing platform

- SMS service to communicate with farmers.

- Web platform to communicate with consumers.
Post-harvest damage mitigation,

- Safe sorting \& storing.

- Introduce railway for vegetable transport.

- Promote GAP to produce quality products, minimize chemical use, minimize hybrid seed use, create a niche market for organic vegetables.

- Reduce stress on outstation farmers, by urban agriculture.

- Promote Traditional knowledge - ex: maze farming in Guatemala

- PAW- state-of-the-art technology.

Eliminate price fluctuations in the value chain

- A data-driven approach for price-fixing.

- Need an independent authority to determine prices.

- Encourage more alternative trading platforms, ex: Embilipitiya - pola \& EC.

- Sorting \& grading of vegetables - sorted vegetables need price discrimination to encourage farmers.

Article by

Asanka O.R.B.E.W. D. Ovitipana,

Sarath Dasanayaka

Department of Management of Technology, Faculty of Business, University of Moratuwa, Sri Lanka. 